\title{
Aplicação de métodos ágeis na gestão de projetos em serviços de engenharia industrial para empresas ME e EPP
}

\section{Application of agile methods in project management in industrial engineering services for ME and EPPcompanies}

\author{
Recebido: 07/09/2020 - Aprovado: 04/01/2021 - Publicado: 02/02/2021 \\ Processo de Avaliação: Double Blind Review
}

\author{
Renato de Brito Sanchez \\ renatobritosanchez@gmail.com \\ Centro Universitário Eniac \\ http://orcid.org/0000-0002-8335-2540 \\ Vinícius de Melo Puglia \\ vinicius_puglia@hotmail.com \\ Centro Universitário Eniac \\ http://orcid.org/0000-0002-1668-289X \\ Erik Cristofer Aparecido Chia \\ erikcristofer51@gmail.com \\ Centro Universitário Eniac \\ http://orcid.org/0000-0002-9291-3477 \\ Ricardo Sanchez \\ ricardosanchez.mrad@gmail.com \\ Universidade Santo Amaro (UNISA) \\ http://orcid.org/0000-0002-9904-5887
}

\section{RESUMO}

No cenário econômico atual, uma das maiores dificuldades é manter a competitividade no mercado, principalmente no segmento de serviços, o qual é volátil e na faixa das micro e pequenas empresas há constantes concorrências acirradas. Diante dessa situação, este trabalho propõe um estudo sobre as técnicas e metodologias de gestão de projetos, visto que uma gestão eficiente permite maximizar o controle das atividades. Dessa forma, é possível prever perdas e ganhos com exatidão. As ferramentas apresentadas permitem uma análise de aplicação tanto de metodologias em cascata, ou seja, as convencionais, quanto as ágeis e permite realizar uma comparação de sua utilização na gestão de projetos em empresas de engenharia com escopos industriais. Considerando todas as peculiaridades desse segmento e, de ambas a metodologias, é possível obter resultados satisfatórios, pois esse porte de empresa consegue se flexibilizar para adaptar ambos os métodos e assim gerir cada projeto por sua especificidade obtendo assim êxitos tanto financeiros quanto operacionais. Empresas de micro e pequeno porte precisam estar

REMIPE- Revista de Micro e Pequenas Empresas e Empreendedorismo da Fatec Osasco 
abertas às opções disponíveis e definir procedimentos e processos, mas não se sujeitar a gerir seus projetos entre métodos convencionais ou ágeis, pois tendem a ter um risco maior que grandes companhias e suas reservas, logo é necessário para cada empresa desenvolver as técnicas que melhor lhe satisfaçam em sua atuação.

Palavras-chave: gestão de projetos; projetos de engenharia; gestão em projetos de engenharia; gestão de projetos em microempresas; gestão de projetos em pequenas empresas.

\begin{abstract}
In the current economic scenario, one of the biggest difficulties is maintaining competitiveness in the market, especially in the service segment, which is volatile and in the micro and small companies range there is a constant fierce competition. Given this situation, this work proposes a study on the techniques and methodologies of project management, since efficient management allows maximizing the control of activities, thus it is possible to predict losses and gains accurately. The presented tools allow an analysis of the application of both cascading methodologies, that is, the conventional, as the agile ones which allow to make a comparison of its use in the project management in engineering companies with industrial scopes. Considering all the peculiarities of this segment and both methodologies, it is possible to obtain satisfactory results, as this company size can be flexible to adapt both methods and thus manage each project by its specificity thus obtaining both financial and operational successes. Micro and small companies need to be open to available options and define procedures and processes, but they can't subject to manage their projects through conventional or agile methods, as they tend to be at greater risk than large companies and their reserves, so it is necessary that each company might develop the techniques that best satisfy them in their performance.
\end{abstract}

Keywords: project management; engineering projects; engineering project management; project management in micro companies; project management in small companies.

\title{
1. INTRODUÇÃO
}

REMIPE- Revista de Micro e Pequenas Empresas e Empreendedorismo da Fatec Osasco

V. $7 \mathrm{~N}^{\circ} 1$ mar.-ago. 2021 
2.

O segmento empresarial está em uma linha de recuperação de um cenário de crise econômica no Brasil, principalmente onde a tomada de preço em serviços requer atenção para uma competição sadia. Diante desse ambiente de preocupação, as micro e pequenas empresas que, até então, tinham uma atuação com maior flexibilidade de trabalhar custos, precisaram reformular suas operações para garantir sustentabilidade em seus negócios.

Uma forma de manter essa viabilidade operacional é manter a execução das atividades com uma eficiência elevada para tantas empresas que não tinham uma sólida ferramenta de gestão, não apenas administrativa, mas para a execução de suas atividades tanto estratégica quanto operacional, tiveram que estabelecer e inserir em seus processos ferramentas e métodos de gestão de projetos.

Este trabalho tem como objetivo apresentar uma análise da aplicação de Métodos Ágeis na gestão de projetos em serviços de engenharia em escopos industriais, de modo a apresentar resultados que possam verificar a viabilidade de sua utilização em empresas estabelecidas como Microempresas e Empresas de Pequeno Porte.

Atualmente, as empresas estão inseridas em um ambiente altamente competitivo, principalmente pela elevada velocidade com que as mudanças tecnológicas ocorrem, além do cenário econômico que pulveriza com facilidade diversas oportunidades de negócios. Todavia, um dos desafios enfrentados é o crescimento empresarial com solidez e que seja autossustentável. Com isso, torna-se importante estudar e desenvolver modelos de maturidade em projetos, visto que se tornam precedentes para implantar estratégias de gestões eficientes, conforme Bouer (2005), por mais singular que seja a metodologia aplicada, o fato de a empresa adotá-la representa um sinal de maturidade da gestão.

Apesar da importância cada vez maior dos projetos nas organizações, a maioria dos projetos não cumpre suas metas. Entregar projetos que atendam às metas de prazo, custo e especificações planejadas e que também atendam aos objetivos de negócio que o justificaram é ainda um desafio a ser superado nas empresas. Pesquisas indicam que somente $28 \%$ dos projetos de tecnologia da informação têm sucesso, que projetos de construção e reforma têm atrasos médios de $103 \%$ e que somente um em cada quatro produtos desenvolvidos se torna um sucesso comercial (CHAOS REPORT, 1995).

As micro e pequenas empresas apresentam relevância incontestável para o desenvolvimento de um país e para a geração de emprego e renda. No Brasil, essas organizações têm sido foco de interesse de estudos das áreas de empreendedorismo e administração de forma

REMIPE- Revista de Micro e Pequenas Empresas e Empreendedorismo da Fatec Osasco 
crescente. Embora isso, há grande espaço para o desenvolvimento de pesquisas no contexto dessas organizações, para geração de conhecimento mais específico e disseminação junto ao ambiente organizacional (MARQUES JUNIOR, 2012).

Em decorrência das atuais mudanças, evidencia-se um gigantesco aumento dos recursos para o método de projeto e do número e diversidade de novos projetos e conceitos. Sendo assim, a gestão de projetos ganha mercado e espaço diante da administração, pelo fato de, na execução de projetos, ser considerada provedora de velocidade, robustez, consistência e excelência operacional (NORO, 2012).

\section{REFERENCIAL TEÓRICO}

4.

Este trabalho se desenvolveu com uma pesquisa para a análise do cenário atual da gestão de projetos nas micro e pequenas empresas, em que segundo o repórter da Agência Brasil, Pedro Rafael Vilela (2019), em sua matéria com dados do Sebrae, o Produto Interno Bruno (PIB) brasileiro neste setor empresarial é composto por uma parcela que representa $25 \%$, sendo esse um índice, embora expressivo, ainda pequeno se comparado com países como Reino Unido, Alemanha, Itália e Holanda, em que esse índice comumente é superior a 50\%.

Para uma análise efetiva e contextualizada sobre a gestão de projetos, especificamente em empresas de engenharia, a pesquisa foi dividida em duas etapas, sendo a primeira uma pesquisa documental com intuito de apresentar a situação atual no Brasil e as características das metodologias aplicadas, posteriormente, uma pesquisa exploratória com um estudo de caso, na qual tem o intuito de demonstrar como as metodologias podem ser aplicadas e como impactam as empresas desse segmento.

\subsection{Cenário atual da Gestão de Projetos}

Como resultado da Segunda Guerra Mundial, em meados do século XX, houve uma grande cooperação no setor de projetos, onde a necessidade de aumentar produtividade em um tempo menor foi ganhando importância nas operações.

Podemos citar a bomba atômica como desfecho do Projeto Manhattan, onde cerca de cem mil pessoas estavam comprometidas no projeto de pesquisa e desenvolvimento. Cientistas, engenheiros, militares e diversos outros profissionais estiveram mobilizados em torno desse 
empreendimento e suas ações foram reunidas em um só objetivo, por meio de organização, planejamento e, claro, produtividade.

A partir disso, as companhias demonstraram interesse em usufruir do gerenciamento de projetos para efetivar a produtividade. É válido ressaltar que a necessidade de suprimentos forçou o aumento da demanda, exigindo ainda mais os recursos da produtividade.

Harold Kerzn se destacou no setor de gerenciamento, ganhando notoriedade em sua forma de ordenar a produção contando com três pilares sendo eles tempo, escopo e custos.

Na Segunda Revolução Industrial, com o advento da eletricidade e do motor movido à combustão, foram desenvolvidas e aperfeiçoadas novas tecnologias de produção em massa para dar maior controle e organização no gerenciamento de projetos (BERNARDO, 2013).

Enquanto na Terceira Revolução Industrial, com o advento dos computadores, e nas décadas seguintes, a Segunda Guerra Mundial, com a criação dos complexos diagramas de rede, chamados de Gráficos de PERT (Program Evaluation and Review Technique) e o método de Caminho Crítico (Critical Path Method - CPM) pelos militares dos EUA, foram introduzidos novos elementos oferecendo aos gerentes maior controle sobre os projetos. Em pouco tempo, essas técnicas se espalharam entre as diversas indústrias e organizações, onde o maior controle e gestão tornavam-se algo estratégico (TORREÃO, 2007).

O Project Management Institute (PMI) foi fundado em 1969, sediada na Pennsylvania, EUA, como uma respeitável instituição para fusão de profissionais especializados em gerenciamento de projetos. Sendo uma instituição sem fins lucrativos com o objetivo de auxiliar gestores no sucesso organizacional.

Segundo Morris (1994), o gerenciamento de projetos se desenvolveu entre o final da década de 60 e o início da década de 70, sendo importante para o desenvolvimento da indústria que passava por um processo de crescimento competitivo.

Durante a década de 90 , notou-se que as metodologias tradicionais já não estavam atendendo a sua finalidade, enfrentando dificuldades de adaptação às necessidades das empresas, além da alta frequência na falha ao cumprir cronogramas e orçamentos pré-definidos.

Nesse cenário, surgiram os métodos ágeis com abordagem harmoniosa e flexível em um setor com constantes mudanças e progressos significativos, como a indústria que a cada ano emprega novas tecnologias visando um melhor preparo para as mudanças e em espaços de tempo cada vez menores. A proposta de metodologias ágeis atende essas demandas, dividindo o desenvolvimento da proposta em ciclos, que duram um pequeno espaço de tempo e que, ao final, o cliente já pode observar os resultados começando a aparecer, agregando com isso valor

REMIPE- Revista de Micro e Pequenas Empresas e Empreendedorismo da Fatec Osasco 
ao negócio. Logo, ao início de cada ciclo, as mudanças de requisitos podem ser monitoradas e alteradas, minimizando os riscos do projeto, uma vez que os desenvolvedores passam a ter um feedback frequente do cliente.

Embora a gestão de projetos tenha se consolidado após a Segunda Guerra Mundial, com a necessidade da reestruturação da indústria, ao longo dos anos, mesmo no período que antecedeu a industrialização, alguns métodos desenvolvidos foram importantes para marcar divisores e quebras de paradigmas operacionais. Essas mudanças foram precedentes para que estudos específicos fossem desencadeados e, dessa forma, proporcionando que a gestão de projetos fosse considerada como um estudo nas ciências. A Figura 1 apresenta uma linha do tempo histórica que que se inicia com grandes construções antigas até 2012, com a consolidação efetiva de metodologias que permitiram a criação de diversas outras utilizadas mundialmente nos mais diversos segmentos empresariais.

Figura 1 - Linha do tempo do gerenciamento de projeto:

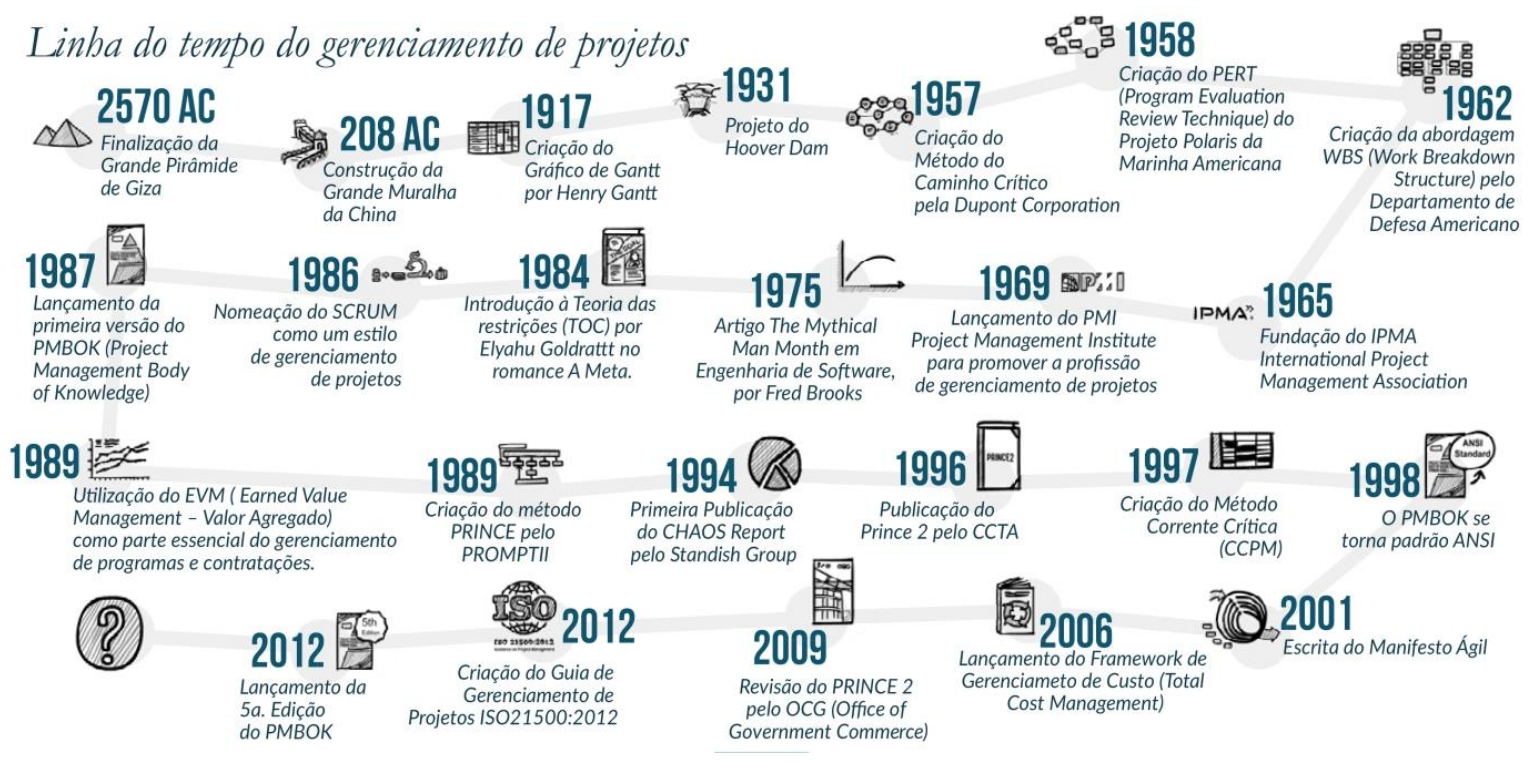

Fonte: UVAGP, 2018.

Nos últimos anos, diversas empresas têm gasto quantidades significativas de recursos em gerenciamento de projetos. O PMI (2009) apresenta um número de US\$ 12 trilhões, sendo esse correspondente a um quinto do valor do PIB mundial, como o valor a ser investido em projetos em cada um dos anos da atual década. Apesar disso, não se encontra uma grande quantidade de pesquisas a respeito do retorno do investimento em métodos de gerenciamento de projetos. Com isso, mesmo com o alto grau de investimento em projetos e o crescente

REMIPE- Revista de Micro e Pequenas Empresas e Empreendedorismo da Fatec Osasco 
número de gerentes de projetos qualificados, algumas questões sobre os resultados e benefícios com esses investimentos surgem (IKA, 2009).

A mudança não é mais vista como algo ruim, pois hoje em dia ela se remete ao aperfeiçoamento contínuo. Conflitos não são mais vistos como prejuízo para a organização, pois, se resolvidos de forma correta, podem gerar benefícios para a empresa. A gestão de projetos também não é mais vista apenas como um sistema de interesse do plano interno das organizações e, sim, passou a ser tratada como uma arma competitiva, que representa níveis crescentes de qualidade e ainda agrega valor aos interesses dos clientes (NORO, 2006).

\subsection{Metodologias para a Gestão de Projetos}

Entre os processos de gestão mais difundidos e de maior complexidade, destaca-se o PMBOK, definido como um conjunto de genéricos e bastante abrangente que objetiva atender às necessidades dos mais diversos tipos de projetos (PMI, 2008). Por isso mesmo, deve ser adaptado quando da aplicação de seus conceitos por parte das organizações. Durante a adaptação, é grande a chance da organização se perder no grau de profundidade com que deve tratar os 42 processos presentes no documento, frente às suas necessidades específicas. Além disso, se a organização também conduz programas, deve buscar os conceitos adicionais e específicos na norma de programa publicada pelo PMI (PATAH, 2012).

Conforme a Figura 2, observam-se as propriedades que cada ferramenta proporciona, servindo de apoio e orientação para o sucesso do projeto.

Figura 2 - Métodos em gerenciamento de projetos e suas principais características: 


\begin{tabular}{|c|c|c|}
\hline Conjunto de métodos & Caracteristicas & Diferenças dos demais \\
\hline $\begin{array}{l}\text { PMBoK - Project Management Body } \\
\text { of Knowledge }\end{array}$ & $\begin{array}{l}\text { Conjunto de métodos desenvolvidos para diversos } \\
\text { tipos de projetos, sendo, portanto, bastante genérico. } \\
\text { Estruturado por áreas de conhecimento de um projeto. }\end{array}$ & $\begin{array}{l}\text { É complementado por dois conjuntos de } \\
\text { métodos adicionais: Programa e Portfólio. }\end{array}$ \\
\hline ICB - IPMA Competence Baseline & $\begin{array}{l}\text { Estruturado por competências que o projeto necessita } \\
\text { desenvolver, divididas em: contextuais, comportamentais } \\
\text { e técnicas. }\end{array}$ & $\begin{array}{l}\text { Juntamente com a norma australiana, } \\
\text { apresenta um grau de profundidade } \\
\text { bem maior que os demais métodos nos } \\
\text { aspectos humanos da figura do gerente } \\
\text { do projeto. }\end{array}$ \\
\hline $\begin{array}{l}\text { AlPM Professional Competency } \\
\text { Standards for Project Management }\end{array}$ & $\begin{array}{l}\text { Esse documento, publicado pelo instituto australiano de } \\
\text { projetos, é bastante similar em sua estrutura ao PMBoK, } \\
\text { dividido por áreas de conhecimento. }\end{array}$ & $\begin{array}{l}\text { Também possui um enfoque mais } \\
\text { profundo nas habilidades humanas. }\end{array}$ \\
\hline APM Body of Knowledge & $\begin{array}{l}\text { Um dos mais completos conjuntos de métodos, esse } \\
\text { documento apresenta conteúdos relacionados a projetos, } \\
\text { valor, escritório de projetos e aspectos estratégicos da } \\
\text { geståo de projetos. }\end{array}$ & $\begin{array}{l}\text { É o mais abrangente dos conjuntos de } \\
\text { métodos. }\end{array}$ \\
\hline $\begin{array}{l}\text { PRINCE2 - Projects in Controlled } \\
\text { Environments }\end{array}$ & $\begin{array}{l}\text { Conjunto de métodos estruturados por etapas de um } \\
\text { projeto e nas atividades a serem conduzidas pela sua } \\
\text { equipe de geståo. }\end{array}$ & $\begin{array}{l}\text { Conjunto de métodos mais voltado para } \\
\text { projetos de tecnologia de informaçåa. }\end{array}$ \\
\hline $\begin{array}{l}\text { ENAA Model Form-International } \\
\text { Contract for Process Plant } \\
\text { Construction }\end{array}$ & $\begin{array}{l}0 \text { documento tem um enfoque muito grande nos } \\
\text { aspectos contratuais de um projeto. }\end{array}$ & $\begin{array}{l}0 \text { foco desse conjunto de métodos såo } \\
\text { projetos de construçåa em engenharia. }\end{array}$ \\
\hline
\end{tabular}

Fonte: PATAH, 2012.

Em contraponto, as metodologias convencionais, o desenvolvimento de processos ágeis enfatizam a importância do planejamento adaptativo, simplicidade e liberação contínua de software com valor operacional em pequenas interações com tempo fixado.

Os métodos ágeis tratam o desafio de um mundo imprevisível confiando na criatividade das pessoas e não nos processos (DYBÅ, 2000). Essas metodologias tendem a tratar todo processo com maior praticidade permitindo com que usuários não necessitem de treinamento específico ou propriamente um conhecimento na área de gestão. Tal forma atende necessidades de empresas de menor porte e com pouca possibilidade de recursos.

Diversas ferramentas estão disponíveis no mercado hoje em dia, criando assim uma competitividade que traz benefícios aos usuários. O Scrum pode ser citada como exemplo de uma ferramenta que a partir de ciclos divide o projeto gerando sprints que são escorados mensalmente, enquanto o Canvas é um método de gerenciamento estratégico que desenvolve e planeia modelos de negócio em blocos para uma pré-visualização de um novo projeto ou mesmo já em andamento. Segundo Carvalho e Mello (2009), dentre os diferentes métodos ágeis, o que mais se destaca é o Scrum, um framework para desenvolvimento de produtos complexos, concebido por Jeff Sutherland e Ken Schwaber.

Apesar dessas ferramentas já estarem mais estruturadas, nada impede o surgimento de outras que também pode contemplar as necessidades específicas de determinado projeto, tais

REMIPE- Revista de Micro e Pequenas Empresas e Empreendedorismo da Fatec Osasco

V. $7 \mathrm{~N}^{\circ} 1$ mar.-ago. 2021 
como, a Trello, Monday, Wrike que apresentam versões gratuitas que podem se estender para a versão paga, porém, mais completa dependendo da necessidade.

Em um conceito macro, as metodologias de projeto podem ser vistas como complementares desde que aplicadas com uma visão analítica das premissas de cada projeto em sua individualidade. Sendo assim, a Figura 3 sugere exemplos para algumas metodologias, em que devem ser considerados parâmetros nos processos como a dinâmica, a estrutura, a velocidade e a estabilidade:

Figura 3 - Análise da aplicação de metodologias para gestão de projetos:

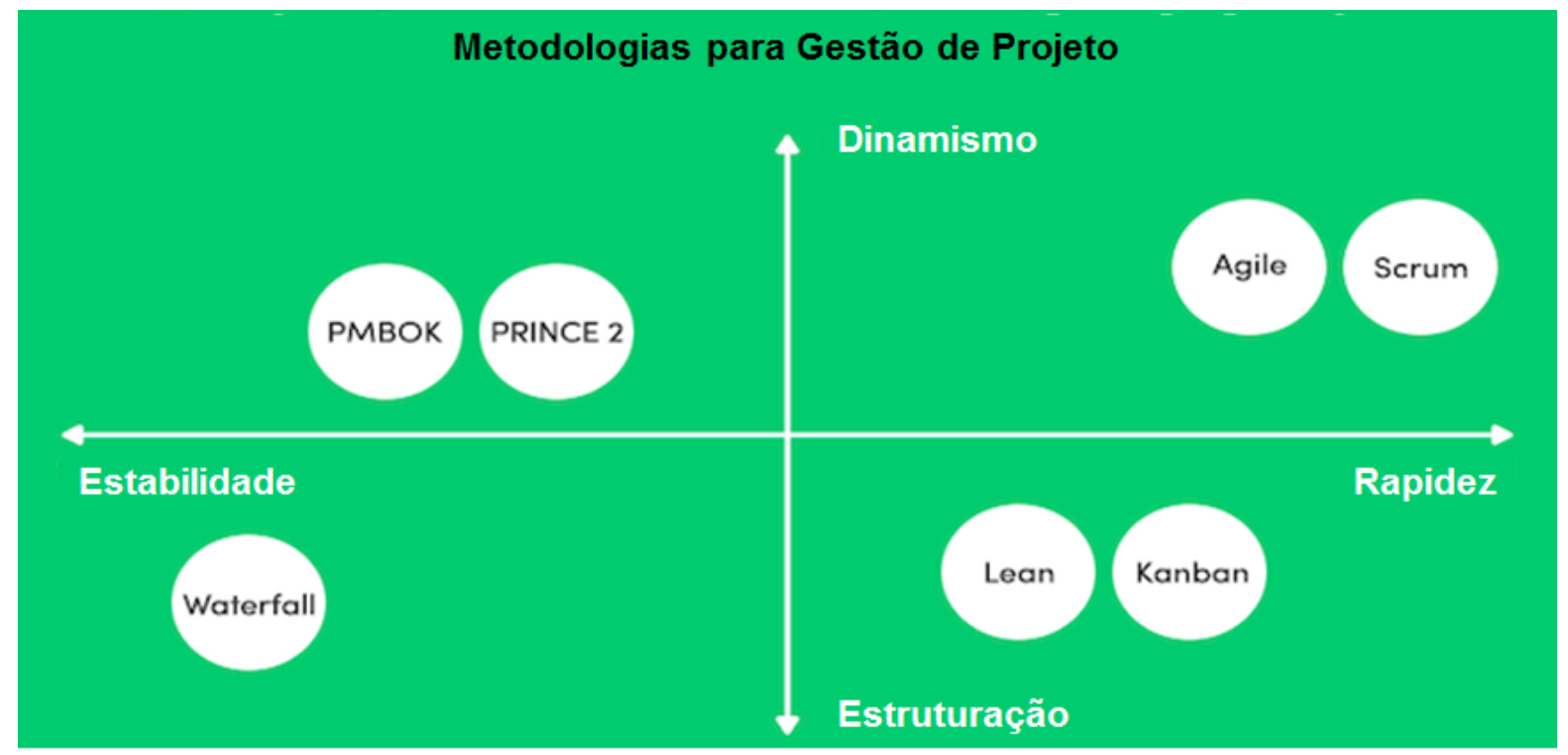

Fonte: Autor (adaptado de Redação Fixe, 2019).

A aplicação de metodologias para o gerenciamento de projetos tem por objetivo conduzir adequadamente todas as atividades envolvidas e prover um processo eficiente. Logo se faz necessário que sejam utilizadas ferramentas que estejam alinhadas com as premissas da empresa. Diante dessas condições, é importante estar atento às metodologias, pois conforme exposto anteriormente há características específicas em cada uma, principalmente, para o setor de serviços, ainda mais no âmbito que compete às empresas de engenharia e serviços técnicos que atendem a indústria, conforme é possível observar abaixo pelas 12 metodologias mais utilizadas mundialmente:

- PRINCE 2: do inglês Project in Controlled Environment, é um método britânico, aplicado em mais de 150 países, com foco no produto e as entregas a serem executadas no

REMIPE- Revista de Micro e Pequenas Empresas e Empreendedorismo da Fatec Osasco

V. $7 \mathrm{~N}^{\circ} 1$ mar.-ago. 2021 
decorrer do projeto, considerando os seguintes princípios básicos: justificativa para o desenvolvimento do projeto; aprendizado com erros e acertos passados; repartição bem definida de papéis; divisão do projeto em estágios; tolerância com adversidades; foco nos resultados; grau de flexibilidade. Essa metodologia faz a gestão de todo o projeto, desde o início, com idealização e estudo de viabilidade até as atividades que envolvem as fases de controle, revisão e monitoramento para que o projeto seja finalizado.

- PMBOK: é um guia elaborado pela PMI no qual traz as melhores práticas em gestão de projetos. O documento é atualizado periodicamente pela entidade gestora e disponibilizado para ser aplicado, sendo dividido em 10 áreas de conhecimento que permitem os gestores planejar, executar e controlar todo o projeto, sendo essas os processos de gerenciamento: da integração; do escopo; do tempo; de custos; da qualidade; de recursos humanos; de comunicações; de riscos; das aquisições; das partes interessadas. Atualmente, o PMBOK é considerado o modelo mais utilizado mundialmente, sendo a bíblia da gestão de projetos para muitos gestores.

- Scrum: é uma metodologia ágil que integra práticas focadas em rapidez e atuação eficiente das ações da equipe, em que considera para esse objetivo a utilização de ferramentas de software, assim como a participação ativa do cliente. O Scrum tem aplicação no desenvolvimento de produtos, sendo facilmente adaptada para serviços. O foco dessa metodologia é executar o projeto em pequenas etapas, denominadas de Sprints, as quais tem duração máxima de até 4 semanas e, ao final de cada etapa, a equipe de projeto se reúne para discutir e revisar as atividades apontando fatores de sucesso e fracasso para a prática da melhoria contínua.

- Caminho crítico: desenvolvida na década de 1950, esta metodologia considera as tarefas em qualquer projeto são dependentes entre si. Dessa forma, há um caminho crítico a ser seguido, pois as tarefas serão executadas apenas se suas predecessoras estiverem completas. Desse modo, é importante que o gestor do projeto consiga priorizar as atividades, pois um bloqueio de caminho pode gerar elevados prejuízos e atrasos, e embora possa ter mais de um caminho crítico, a melhor forma de visualização é por meio de um diagrama de redes.

- $\quad$ Project Model Canvas: uma das mais conhecidas e utilizadas metodologias para gestão de projeto, onde propõe a substituição de toda a documentação, projetos e demais papéis por

REMIPE- Revista de Micro e Pequenas Empresas e Empreendedorismo da Fatec Osasco 
uma tela que reúne as informações do projeto. Considerada simples, seu foco é que as informações tanto do planejamento quanto para a condução estejam visíveis e possam ser compreendidas e discutidas entre o gestor e a equipe, logo, sua compreensão se baseia em seis perguntas fundamentais: por quê?; o quê?; quem?; como?; quanto?; quando?. Quando respondidas permitem uma visão clara das ideias, assim como permite adequar a tela.

- Gestão da qualidade: baseada nas normas ABNT NBR ISO 9000 (Sistema de Gestão de Qualidade) e ABNT NBR ISO 10006 (diretrizes para a qualidade no gerenciamento de projetos), tem como foco garantir a padronização da gestão de projetos, considerando certificar sua qualidade independente do seu escopo.

- Six Sigma: embora não seja considerada uma metodologia para a gestão de projetos, é uma ferramenta eficiente se aplicada, que se baseia em estatísticas para medir as inconformidades de um produto ao longo de seu desenvolvimento com foco em eliminá-la, pois por padrão o resultado deve possuir um percentual de acerto de 99,9996\%. Tal índice é almejado por meio de dois principais processos baseados no PDCA (Plan - Do - Check - Act), sendo o DMAIC (Define; Measure; Analyse; Improve; Control) e DMADV (Define; Measure; Analyse; Design; Verify). Ressalta-se que diversas empresas combinam os conceitos de Six Sigma e Lean para obter em processos eficientes e econômicos resultados que visam elevados níveis de qualidade.

- $\quad$ MPMM: o Project Management Methodology (MPMM) é uma metodologia baseada no PMBOK e no PRINCE 2, criada pela empresa Methods 123 Ltd., a qual tem foco em elaborar e gerir projetos com eficiência. Sendo apresentada por pacotes, onde: a Standard é versão destinada aos pequenos e médios com apenas um computador; a Professional atende até 20 usuários sendo aplicada a qualquer porte de projetos; e a Enterprise como a versão para número elevador de operadores, além de permitir trabalhar simultaneamente com uma grande quantidade de projetos.

- Methodware: desenvolvido em duas versões, sendo a Convencional com 30 processos, e a Básica que totaliza apenas 13, onde independentemente da versão, são agrupados nas etapas: Planejamento; Execução; Monitoramento; Controle; Encerramento. Como ferramenta para elevar sua eficiência é permitido aplicar uma matriz RAB, em que é possível elaborar uma

REMIPE- Revista de Micro e Pequenas Empresas e Empreendedorismo da Fatec Osasco 
planilha com notas atribuídas por métricas pré-definidas que definem a importância de cada tarefa.

- Zoop: originada na Alemanha, entre os anos de 70 e 80, esta metodologia tem por base o Planejamento de Projetos Orientados por Objetivos (do alemão Zielorientierte Projektplanung), em que a gestão é realizada em quatro tarefas, sendo: análise; elaboração; colocação em prática; avaliação dos processos e resultados. Como principal vantagem é destacada oportunidade da participação popular que considera a interação com comunidades, grupos, cooperativas e no uso por organizações do Estado.

- TenStep: este método é baseado em realizar 10 passos, sendo que a primeira e a segunda etapas realizadas em ordem, porém as demais se admite a flexibilidade de executá-las aleatoriamente conforme as necessidades e premissas do projeto. Com o foco em definir o projeto e elaborar o programa, em sequência das duas primeiras etapas é permitido investir em qualidade, mudanças, riscos e medidas, ainda considerando que a terceira etapa prevê a integração do projeto por atuar com o cronograma e o orçamento.

- Waterfall: esta metodologia tem fácil entendimento, sendo conhecida mundialmente, cujo objetivo é executar sequencialmente as etapas do projeto, considerando uma ordem lógica que almeja um determinado resultado. Tem como princípio que uma tarefa apenas inicie quando sua predecessora for finalizada, todavia, como viés não prevê alterações no escopo, logo, seria necessário interromper e refazer o projeto, resultando em transtorno e prejuízos elevados. Embora seja uma metodologia tradicional e não flexível, ainda assim é largamente aplicada nos segmentos de fabricação e construção.

É fato que atualmente há diversas metodologias para a gestão de projetos, principalmente considerando o histórico apresentado e a premissa de que podem ser flexibilizadas com a finalidade de atender de forma eficiente um dado segmento ou mesmo projetos específicos que venham a ocorrer por necessidade da modernização e expansão da tecnologia nos mais diversos segmentos empresariais. Todavia, o que irá definir a melhor aplicação e a escolha de uma metodologia dentre suas características específicas será um estudo detalhado das reais necessidades tanto da figura representada pelo fornecedor quanto do 
REMIPE

tomador desse projeto, assim como é imprescindível que a definição do nível de gestão almejado e que todo este processo e metodologia esteja alinhada e de domínio do gestor.

\subsection{Aplicação da Gestão de Projetos em Micro e Pequenas Empresas}

Com métodos de gestão utilizados, pode-se atingir níveis elevados de produtividade e performance, com ganhos aos clientes e à equipe executante. Formalizações mínimas sempre serão necessárias. E, atualmente, o volume de informações e a agilidade com que surgem novas solicitações obriga que os times sejam ágeis. Só assim, a qualidade percebida será mantida ao longo do desenvolvimento e culminará em uma entrega final que contemple os requisitos exigidos pelo cliente (BARBOZA, 2016).

A implantação da ferramenta de gestão de projetos, proposta pelo PMI, surge eficaz, pois permite medir, avaliar e divulgar os resultados da empresa. Porém, com a realidade dos sistemas de gestão existentes nas empresas, as organizações encontrarão algumas dificuldades na implantação da gestão de projetos por possuírem controles de gestão superficiais, tendo que criar o hábito de controle, planejamento e disciplina para seguir um cronograma e orçamento aprovados. Também, por serem atividades não contínuas na empresa, existe o risco de o gestor "confundir" e misturar as atividades, não conseguindo avaliar o que pode ser gerido por essa ferramenta. E em relação à equipe, essa pode sofrer resistência na implantação do novo modelo de gestão que vem para complementar o que já existe (SELLA, 2011).

$\mathrm{Na}$ verdade, não existe um procedimento padrão para o gerenciamento de projetos, o procedimento deve ser adaptado para cada tipo de projeto (HIRAYMA, 2016). Isso se torna evidente visto, pois cada ferramenta possui sua particularidade dentro do contexto apresentado.

Devido à escassez de recursos disponibilizados pela empresa, o gestor de projetos busca cada vez mais uma solução eficaz, àquela da qual visa se aplicar um baixo custo com um alto benefício tornando o encargo de alcançar a ferramenta de gestão ideal mais árduo. A tarefa de encontrar a ferramenta certa é tão complexa quanto sua utilização no decorrer do projeto, em função disso é passivo de uma avaliação quanto às particularidades específicas dele. Apesar da similaridade das ferramentas de processos ágeis a sua grande diferença se depara na característica do projeto a ser manejado, assim como o nível de instrução dos profissionais que terão acesso à ferramenta possuem.

Em uma outra exemplificação, o Rational Unified Process, conhecido como RUP, é um processo de engenharia de software criado para apoiar o desenvolvimento orientado a objetos,

REMIPE- Revista de Micro e Pequenas Empresas e Empreendedorismo da Fatec Osasco 
fornecendo uma forma sistemática para se obter vantagens no uso da Linguagem Unificado de Modelagem. Dessa forma, ele atende as necessidades dos usuários garantindo uma produção de software de alta qualidade que cumpra um cronograma e um orçamento previsíveis. Segundo Alves (2011), é possível integrar práticas ágeis no RUP de tal modo que sua estrutura centrada em arquitetura e guiada por risco possa ser mantida e, ao mesmo tempo, ganhos reais em produtividade possam ser obtidos. Isso mostra a relevância da ferramenta dentro de um projeto de produtividade onde há uma integração entre o processo Scrum baseado em RUP.

\section{ESTUDO DE CASO}

Diversas empresas nesse cenário de competitividade buscaram soluções para se adequar e se tornar competitivas, como exemplo, o Grupo Engerisa, de origem brasileira, que reúne duas empresas, sendo uma a Engerisa Engenharia e Consultoria, classificada como Micro Empresa com atividades de projetos, consultorias e serviços de engenharia e outra, a Engerisa Tecnologia em Automação, classificada como Empresa de Pequeno Porte, com atividades de serviços técnicos industriais, prediais, máquinas e equipamentos.

O grupo iniciou as atividades em 2002, com consultorias e projetos, onde inicialmente utilizava técnicas de gestão singulares por meio de planilhas, formulários e documentos de textos. O período era propício e com um número reduzido de clientes era possível manter o controle de cada etapa e processo na gestão, porém com a modernização do mercado e a expansão na carteira de clientes, a Engerisa se viu na necessidade de otimizar suas técnicas e métodos, mas diante do impasse de que as metodologias convencionais eram demasiadas e as ágeis ainda uma nuvem misteriosa, foi necessária uma adaptação de métodos, em que iniciou trabalhos de digitalização.

Atualmente, o Grupo Engerisa atende clientes não apenas no território brasileiro, desde pequenos projetos a grandes com etapas de comissionamento e startup. Nesse cenário, há atividades e necessidades com uma elevada dinâmica e por estar em diversos segmentos não é possível se utilizar de um único método. Logo, as metodologias convencionais não garantem a agilidade de flexibilidade no decorrer do cronograma, assim como as metodologias ágeis em determinados casos favorecem a perda de informação e o retrabalho, pois em atividades a longas distâncias, mesmo que virtual, fazem com que reuniões e alinhamentos constantes sejam um ponto de entrave desnecessário.

REMIPE- Revista de Micro e Pequenas Empresas e Empreendedorismo da Fatec Osasco 
Os projetos e serviços são geridos com sua elaboração pela base do que diz a Metodologia em Cascata, ou seja, pelos métodos convencionais, porém devido à diversificação dos clientes e, para permitir que mesmo em projetos pequenos seja mantida a dinâmica e agilidade nas entregas com as devidas validações e qualidade, as tratativas tanto com o cliente quanto entre a equipe, utilizando de ferramentas como sprints para em curtos períodos analisar e tomar decisões em cada etapa do cronograma.

Antes do início de um projeto a equipe responsável é reunida para as definições e premissas, onde é aberto o Termo de Abertura e os demais documentos e processos indicados pelo guia PMBOK, porém as etapas menores ou os micro projetos que venham a ocorrer dentro do projeto principal, ou mesmo os que ocorrem de forma mais simples diretamente com os clientes, são tratados com ferramentas das metodologias ágeis, como o uso de sprints, no qual as ações de curta duração e o acompanhamento de etapas maiores são realizados por meio da análise de indicadores e reuniões rápidas de alinhamento entre a equipe, o gestor do projeto e o cliente. Sendo assim, as flexibilizações e tomadas de decisão para mudanças favoráveis ao desenvolvimento do projeto são analisadas no denominado tempo real quanto aos riscos e viabilidade, de modo que as ações são imediatas.

Um exemplo disso, foi um trabalho realizado pela Engerisa Engenharia e Consultoria, em um de seis clientes, a qual é uma empresa no segmento de conformação de borrachas e elastômeros localizada na Zona Leste da cidade de São Paulo, SP, a qual teve a necessidade de adequação as boas vigentes e a implantação plena da Norma do Ministério do Trabalho e Emprego, NR-12, que trata da segurança em máquinas e equipamentos. Por ser de pequeno porte e com cenário brasileiro de crise econômica, essa empresa não poderia dispor de grandes investimentos, porém tinha prazo conforme legislação trabalhista.

Com essas premissas, a Engerisa propôs uma solução dividida em ciclos, começando pela apresentação da solução e criação de um primeiro protótipo, visando tanto o estudo dos recursos que seriam empregados para elaboração desse trabalho, como também, estudar qual impacto isso teria na empresa, tanto em fluxo financeiro quanto em produtividade, nos processos de fabricação. Portanto, não oferecer uma proposta que, por sua vez, afetaria diretamente o rendimento ou dificultaria o trabalho dos funcionários.

$\mathrm{Na}$ primeira fase do ciclo ficou estabelecido o levantamento de informações e a apresentação para a empresa de como iria ocorrer e, que também, é um método seguro que não impactaria na produção, com o feedback fornecido pelo cliente. A Engerisa pôde dar prosseguimento na próxima etapa do ciclo, dividindo a realização do projeto em fases mais

REMIPE- Revista de Micro e Pequenas Empresas e Empreendedorismo da Fatec Osasco 
ágeis e rápidas nessa segunda etapa, dividindo o trabalho em um espaço de tempo e que ao final de cada etapa, era levantado mais informações e o feedback do cliente, o que permitiu por meio de indicadores internos visualizar posterior a segunda etapa e contando com histórico da primeira que houve um retorno positivo e viável após implantação, com a redução do tempo necessário para a realização do trabalho do funcionário tendo um ligeiro ganho na produção e, com isso, um menor gasto de recurso que, nesse caso, é a energia gasta para realizar o trabalho.

\section{RESULTADOS}

6.

Ficou evidente que mesmo tendo um projeto macro gerindo a conta desse cliente com bases no PMBOK, os Métodos Ágeis flexibilizaram as operações de micro projetos e implantações com tomadas de decisão mais rápidas e uma análise em tempo real com o cliente, pois cada parte do ciclo de vida dessa implantação permitiu que a empresa visualizasse em seus indicadores e relatórios que havia valor agregado ao negócio e sem despender investimentos inviáveis para cumprir o cronograma e manter a qualidade dos entregáveis.

A exemplo e validação das aplicações de metodologias no Grupo Engerisa para com seus clientes, o desempenho dos projetos com a adaptação de ambos os métodos para serem utilizados em conjunto permitiu que as empresas do grupo, comparando sua atuação com a aplicação de apenas uma das metodologias, diminuísse as perdas internas com tempo e implantações em $35 \%$, assim como conseguiu expandir em $43 \%$ a abrangência da equipe em atuar gerindo atividades dentro dos clientes, também foi possível otimizar em $15 \%$ o tempo de atuação e entrega de projetos e $8 \%$ de aumento de demanda por equipe dentro da mesma operação e sem acréscimos de horas e atividades à equipe.

\section{CONSIDERAÇÕES FINAIS}

A importância da gestão de projetos deve considerar a premissa de uma aplicação eficiente e, para isso, todos os envolvidos devem ter plenos conhecimentos sobre os processos e etapas que irão atuar, isso porque a condução do projeto deve ser não apenas operacional e tecnicamente, mas também, de forma administrativa.

No Brasil a cultura de gestão, principalmente em projetos, ainda detém paradigmas, pois embora seja comum em empresas de médio e grande porte, as administrações de micro e pequenas empresas definem como desnecessário ou burocracia, visto que deveriam ter uma

REMIPE- Revista de Micro e Pequenas Empresas e Empreendedorismo da Fatec Osasco 
análise crítica de que uma gestão de projetos eficiente não representa despesas, mas um lucro indireto das atividades, uma vez que as perdas e despesas desnecessárias tendem a ser diminuídas significativamente e até mesmo extintas.

Há uma grande distância a percorrer nesse processo de conscientização e assim como estudos referenciados nesta pesquisa, esta mantém precedentes em elucidar a necessidade e a importância de adotar a gestão de projetos independente do porte empresarial, assim como propõe a continuidade dos estudos para que possa ser obtido um volume maior de dados e uma análise estatística detalhada que permita previsões econômicas e de crescimento para esse segmento das micro e pequenas empresas.

\section{REFERÊNCIAS}

ALVES, Nelio Muniz Mendes et al. Um estudo de caso industrial sobre integração de práticas ágeis no RUP. Revista Ciência e Tecnologia, v. 14, n. 24/25, 2011.

BARBOZA, LIVIA FERNANDES et al. Análise comparativa entre as abordagens ágil e tradicional de gestão de projetos: Um estudo de caso no setor industrial. Anais do Simpósio Internacional de Gestão de Projetos, Inovação e Sustentabilidade, 2016. https://singep.org.br/5singep/resultado/289.pdf

BERNARDO, André. A História do Gerenciamento de Projetos. Responsabilidade do autor do vídeo. YouTube, 2013. Duração: 5min52seg. Disponível em:

<https://www.youtube.com/watch?v=le0GTYjlvl4>. Acesso em: abril de 2017.

BOUER, Ruy; DE CARVALHO, Marly Monteiro. Metodologia singular de gestão de projetos: condição suficiente para a maturidade em gestão de projetos? Production, v. 15, n. 3, p. 347 $361,2005$.

Disponível em: <http://www.scielo.br/pdf/\%0D/prod/v15n3/v15n3a05.pdf> Acesso: nov. 2019

CHAOS REPORT. The Standish Group Report, 1995. Disponível em <http://www.scs.carleton.ca/ beau/PM/ Standish-Report.html> Acesso em: nov. 2019 
REMIPE

DE BEM NORO, Greice. A gestão de stakeholders em gestão de projetos. Revista de Gestão e Projetos-GeP, v. 3, n. 1, p. 127-158, 2012.

Disponível em: <http://revistagep.org/ojs/index.php/gep/article/view/23/279>

DYBÅ, Tore. Improvisation in small software organizations. IEEE Software, 17, 2000, pp. 82-87. Disponível em:

<https://www.researchgate.net/publication/3247653_Improvisation_in_Small_Software_Orga nizations>

HIRAYAMA, Ernesto Toshimitsu et al. Proposta de procedimento para gerenciamento de pequenos projetos: aplicação em dispositivos industriais. 2016.

IKA, L. A. Project success as a topic in project management journals. Project Management Journal, Four Campus Boulevard: Project Management Institute v. 40, n. 4, p. 06-19, 2009.

MARQUES JUNIOR, Luiz José et al. Gestão de projetos em empresas no Brasil: abordagem "tamanho único". Gestão da Produção, v. 18, n. 1, p. 1-12, 2011.

Disponível em: 〈https://core.ac.uk/download/pdf/37445983.pdf〉

MORRIS, Peter WG; MORRIS, Peter WG. The management of projects. T. Telford, 1994.

NORO, Greice. A maturidade em gerenciamento de projetos logísticos: o caso América Latina Logística. Dissertação de mestrado. Universidade Federal de Santa Maria - Centro de Tecnologia - Programa de Pós-Graduação em Engenharia de Produção, 2006. Disponível em: <http://revistagep.org/ojs/index.php/gep/article/view/23/279> Acesso em: nov. 2019.

PATAH, Leandro Alves; DE CARVALHO, Marly Monteiro. Métodos de gestão de projetos e sucesso dos projetos: um estudo quantitativo do relacionamento entre estes conceitos. Revista de Gestão e Projetos-GeP, v. 3, n. 2, p. 178-206, 2012.

Disponível em: <http://www.revistagep.org/ojs/index.php/gep/article/view/94/292> 

. Sucesso a partir de investimento em metodologias de gestão de projetos. Production, v. 26, n. $1, \quad$ p. 129-144, 2016. Disponível em: <http://www.scielo.br/pdf/prod/2015nahead/0103-6513-prod-0103-6513048312.pdf>

PEDRO RAFAEL VILELA (Rio de Janeiro). Agência Brasil (Comp.). Pequenas empresas garantem saldo positivo de empregos, mostra Sebrae. 2019. Repórter da Agência Brasil. Disponível em:

<http://agenciabrasil.ebc.com.br/educacao/noticia/2019-07/pequenas-empresas-garantemsaldo-positivo-de-empregos-mostra-sebrae>. Acesso em: 24 nov. 2019.

Redação FIXE. Frameworks Agile, PMI ou as chamadas metodologias híbridas? FIXE, Porto, Portugal. 2019. Disponível em:

https://youwilldobetter.com/2019/03/frameworks-agile-pmi-metodologias-hibridas/. Acessado em: 27 nov. 2019

SELLA, Verônica Trentin; GRZYBOVSKI, Denize. Modelo PMBOK/PMI para gestão de projetos nas micro e pequena empresas: um estudo de caso. Revista Economia \& Gestão, v. 11, n. 27, p. 36-66, 2011.

http://periodicos.pucminas.br/index.php/economiaegestao/article/view/2833

UVAGPLASS. A evolução do gerenciamento de projetos no Brasil e no mundo. UVAGPLASS, Rio de Janeiro. 2018. Disponível em: https://uvagpclass.wordpress.com/2018/06/11/a-evolucao-do-gerenciamento-de-projetos-nobrasil-e-no-mundo/. Acessado em: 27 nov. 2019

TORREÃO, Paula. História do Gerenciamento de Projetos, 2007. Disponível em: <https://pontogp.wordpress.com/2007/04/23/historia-do-gerenciamento-de-projetos/>. Acesso em: abril de 2017. 